\title{
Characteristics of psychological resilience and body image in women in the early and late periods after mastectomy
}

\begin{abstract}
BACKGROUND
European statistics confirm a rise in breast cancer among women. Those suffering from breast cancer and undergoing mastectomy are undoubtedly experiencing a range of negative and/or positive emotions, thoughts and behaviours that depend on many factors such as psychological resilience. The study reported here aimed to identify factors that protect body image resilience in women suffering from breast cancer after mastectomy.
\end{abstract}

\section{PARTICIPANTS AND PROCEDURE}

The research group comprised 120 women after either a short (up to 2 years) or a long (over 2 years) time since mastectomy. Three scales were applied, namely the Resilience Measurement Scale (SPP-25) developed by Juczyński and Ogińska-Bulik to measure the variability of psychological resilience, the Body Attitude Test (BAT) developed by Probst, and others (Polish version by Brytek-Matera), and Probst's Body Self Questionnaire developed by Mirucka for the measurement of the body image.

\section{RESULTS}

Post-mastectomy patients proved to have a significantly poorer self-assessment of the body, more restrictive eating

\begin{abstract}
behaviours and weight control employed with the aim to improve their appearance. Women just after mastectomy, seemed more focused on mobilising their resources necessary to adapt to new conditions and to restore balance after the difficult experience compared to women who had undergone mastectomy over 2 years before the study. The former are characterised by a higher degree of psychological resilience, higher perseverance and determination in action. They also better cope with experienced failure and negative emotions, which indicates that they have a greater capacity to detach from difficult situations.
\end{abstract}

\section{CONCLUSIONS}

The greater mobilisation of resources necessary to adapt to new conditions and to restore balance after a difficult experience require consideration and application of psychological support from the very beginning of treatment. For this reason, psychological counselling and work on strengthening resilience among women after mastectomy are indicated.

KEY WORDS

resilience; body image in post-mastectomy women; adaptation to restore balance after mastectomy

ORgANIZATION - 1: Institute of Applied Psychology, Jagiellonian University, Krakow, Poland · 2: SWPS University of Social Sciences and Humanities, Warsaw, Poland

aUthors' Contributions - A: Study design - B: Data collection - C: Statistical analysis - D: Data interpretation .

E: Manuscript preparation · F: Literature search · G: Funds collection

CORRESPONDING AUthor - Prof. Bernadetta Izydorczyk, Institute of Applied Psychology, Jagiellonian University,

4 Łojasiewicza Str., 30-348 Krakow, Poland, e-mail: bernadetta.izydorczyk@uj.edu.pl 


\section{BACKGROUND}

In the last decade, Polish research has seldom discussed the issue of psychological resilience and body image as significant psychological variables with a considerable impact on the functioning of postmastectomy women. However, results of scientific studies dedicated to the subject of this article may serve as a significant source of knowledge supporting treatment and recovery of women suffering from breast cancer. Both Polish and foreign statistics confirm a rise in breast cancer among women. In 2008, over 330,000 women were diagnosed with breast cancer in the European Union member states. In 2013, the incidence of malignant breast cancer in women was over 17,000 in Poland (the Polish National Cancer Registry, 2013). According to forecasts for the years 2010-2025, the breast cancer incidence rate is expected to rise from 44 per hundred thousand population by 2006 to 60 per hundred thousand population by 2025 . The forecast breast cancer incidence in women for 2025 is over $50.00 \%$ higher than in 2006 (Meder, 2014).

Both suffering from cancer and undergoing surgery (in this case, mastectomy) are undoubtedly considered difficult situations in psychology. Both situations involve occurrence of traumatic events in a person's life. The range of numerous negative and/ or positive emotions, thoughts and behaviours arising from a difficult situation and an emotional crisis occurring in the course of cancer and invasive procedures depend on many psychological factors, i.e. the resources of a given patient. These include psychological resilience, which is an important factor that protects and supports an individual in recovery experienced in the difficult situation of cancer.

As mentioned above, traumatic events affect one's body experience (Sakson-Obada, 2009a, 2009b; Mirucka \& Sakson-Obada, 2013). Breast cancer and related mastectomy are traumatic experiences that evoke emotions classified as severe emotional stress (Cordova, Studts, Hann, Jacobsen, \& Andrykowski, 2000; Cordova, Cunningham, Carlson, \& Andrykowski, 2001; Ogińska-Bulik, 2010, 2013). Usually, the experience of breast cancer and mastectomy violates a person's balance in the physical (erosion of physical boundaries), the mental (experiencing emotional crisis and, at times, also post-traumatic stress) and the social aspect (social isolation, limited capacity to fulfil family and professional roles). On the one hand, mastectomy is a life-saving procedure, while on the other, it deforms a woman's body, which might additionally intensify her negative self-perception (due to the deformed physical appearance, perceived by the patient and others as unattractive), and provoke excessive anxiety of permanent deformity. In terms of the psyche, the very removal of one breast is associated with a loss of the symbol of femininity and physical attractiveness. As such, this evokes a feeling of a loss and often an experience of disability. As a result, one withdraws from social life and avoids contact with other people (Kozela, Stepaniak, \& Pająk, 2011). Nevertheless, the perception, thoughts or emotions experienced with regard to one's own body after mastectomy may be related to one's mental resources, particularly one's psychological resilience (Okła, Steuden, \& Puzon, 2006; Ogińska-Bulik, 2011; Krok \& Kubiec, 2013). Current literature on the issue discussed in this paper indicates reports concerned primarily with describing selected psychological traits and changes in the body image in post-mastectomy women. However, there are no reports containing detailed research data specifying the psychological profile of post-mastectomy women with regard to the specificity of changes in the body image and, at the same time, describing the intensity of the so-called protective factors in this group of patients, which include psychological resilience. A review on the worldwide and Polish studies on the measurement of the body image in post-mastectomy women proves that the findings are diverse and ambiguous. Some of them indicate absence of differences between post-mastectomy patients and women who have not experienced such a procedure (Tarnopolska, 2007; as cited in Krok \& Kupiec, 2013; Głębocka, 2009), while according to other studies there are some differences reported between healthy women and post-mastectomy patients, indicating that the latter experience a lower sense of attractiveness and higher dissatisfaction with their own appearance (Życińska, 2005). Biological and psychological changes resulting from this procedure are often related to low mood, malaise and altered selfimage and self-perception (Życińska, 2005; Dunn et al., 2011). Post-mastectomy women might experience fear of disability and loss of attractiveness (Głębocka, 2009). Results of Polish studies indicate that the significance of the body image, fears related to physical deformity, the loss of an attribute of femininity, compromised self-attractiveness and lowered sense of self-worth are present in post-mastectomy women (Tarnopolska, 2007; as cited in Krok \& Kupiec, 2013; Życińska, 2005; Głębocka, 2009). In turn, in the studies conducted by Krok and Kubiec (2013), which focused on comparing post-mastectomy women and their daughters to a group of women who did not undergo mastectomy, no significant differences in the overall body image were found between the groups. Differences in the discussed study were reported only regarding sensitivity to criticism from others.

Women who underwent breast removal proved more prone to social criticism despite undertaking no actions aimed at changing the body image. However, daughters of post-mastectomy patients used many methods to improve their appearance (diet, physical activity, proper clothes, makeup). As noted by Krok
Psychological resilience and body image after mastectomy 
Bernadetta Izydorczyk, Anna

Kwapniewska, Sebastian Lizińczyk, Katarzyna SitnikWarchulska and Kubiec (2013) in their joint study, behaviour aimed at improving self-image has a positive effect on body satisfaction, which in turn translated into a greater satisfaction with life. The lack of significant differences regarding the body image among postmastectomy patients and healthy women is said to result from defence mechanisms and coping strategies. This is confirmed by studies conducted by Tarnopolska (2007, as cited in Krok \& Kupiec, 2013), who found that satisfaction with life and satisfaction with specific body parts are positively correlated. In the group of post-mastectomy women, satisfaction was proved to be lower only with regard to breasts, while other aspects of the body image were assessed similarly by both most-mastectomy and healthy participants (Tarnopolska, 2007; as cited in Krok \& Kupiec, 2013).

According to global source literature, post-mastectomy women prove to be considerably more dissatisfied with their body image and femininity compared to women treated due to gallbladder issues, women with negative breast biopsies and healthy women (Fobair et al., 2006). In their study, Tykkä, Asko-Seljavaara and Hietanen (2002) draw attention to poor self-esteem and the need to improve one's appearance among women who have undergone breast reconstruction.

In the research conducted worldwide in the last decade, much attention is drawn to Scandinavian studies proving that in a group of post-mastectomy women only $31.00 \%$ of the participants had a negative body image. As noted by the researchers, this value is not very different to the results obtained for the control group (Falk Dahl, Reinertsen, Nesvold, Fosså, \& Dahl, 2010). The above-mentioned researchers claimed modified radical mastectomy (MRM) and treatment-induced changes in the body (i.e. due to radiotherapy) to be substantially related to a negative body image. Most of the women who had a negative body image were to undergo breast reconstruction or had already undergone this procedure at that time, and moreover completely changed the way they dressed to cover the traces of the surgery. Furthermore, they reported a higher level of depression and anxiety, felt more physically and mentally exhausted and considered their health condition to be worse than that reported in the group characterised by a positive body image. However, the total body image rate in post-mastectomy women and in the control group was not significantly different. Moreover, selfassessment of the body remained relatively stable throughout three years (Falk Dahl et al., 2010). According to results obtained in contemporary worldwide research, women with a more positive body image manifest higher self-confidence in their fight against breast cancer (Pikler \& Winterowd, 2003).

To summarise the above-presented study results on the body image as a variable describing the psychological profile of a post-mastectomy woman, one could reflect on and verify empirically in scientific studies the extent to which the body image constitutes an element of one's personality structure that is not easily modified, which could explain the results of the above-presented studies and insignificant differences in the way post-mastectomy and healthy women perceived their bodies. However, it is worth verifying the extent to which one's mental resources, particularly psychological resilience, serve as a significant factor modifying one's own body image, particularly after invasive medical procedures. The second psychological variable considered significant in the description of the psychological profile of women suffering from breast cancer employed in our research model is psychological resilience. In the literature, psychological resilience is defined within the scope of the notion of resilience (Borucka, 2011). Most often, the literature provides three main theoretical approaches to the definition of psychological resilience. The first one considers psychological resilience "a relatively permanent disposition that determines the process of flexible adaptation to constantly changing life expectations" (Ogińska-Bulik \& Juczyński, 2008, p. 40). The second approach considers psychological resilience as "a set of effective capabilities to cope with severe stress that involves overcoming adversities in a flexible and creative manner; here, the key role is played by the capacity to bounce back from negative experiences and the capacity to evoke positive emotions" (Heszen \& Sęk, 2007 , p. 173). Therefore, it is the capacity to adapt to a change following a crisis, difficulties, and prolonged stressful situations (Ostrowski, 2014). Nadolska and Sęk (2007) clearly stated that resilience results from interactions between an individual and the environment. When experiencing difficult, stressful events, a person benefits from them by acquiring new coping methods. The third approach to defining psychological resilience depicts the presented mental phenomenon as a coping mechanism applied in stressful situations or traumatic events, such as disease or a loss of a loved one. Emotional resources, such as the tendency to experience positive emotions and the capacity to go through a difficult past, as well as the capacity to focus on tasks, high intelligence and diverse stress management strategies, are significant factors that increase resilience (Luthar, 2006; Ostrowski, 2014). Resilience mechanisms are most often related to the effect of individual and social factors (Sęk \& Cieślak, 2004), where the role of the capacity to build social support network and to use others' help is emphasised, which strengthens and develops resilience to difficult events. The most often listed individual resilience mechanisms involve: the capacity to detach emotionally (or even physically) from difficult situations or traumatic experiences, and the capacity to generate positive emotions or, more specifically, to co-create them aside from negative emotions related 
to difficult experiences. Many authors draw attention to cognitive mechanisms that allow one to grow past the experienced stressful events. Ostrowski (2014) speak of "benefit finding" in the context of a difficult situation. It is a re-evaluation mechanism that consists in changing one's perception of a difficult situation and finding some positive aspects to it. They also mention the "sense-making" mechanism, which involves treating difficult experiences as a natural part of human life. According to other researchers (Folkman \& Moskowitz, 2000), positive emotions are related to problem-focused coping and positive reappraisal strategies, as well as infusing ordinary events with positive meaning. In her theory of positive emotions, Fredrickson (2004) stressed that positive emotions serve as the basis for psychological resilience. Positive emotions broaden thinking, thus allowing a person to see more optional solutions to overcome difficult situations and new ways of acting. This capacity to seek various solutions, to broaden one's own perception, builds physical, psychological and social resources of a given individual. In their study, Tugade and Fredrickson (2007) show that people who are more resilient develop positive emotionality by evoking positive emotions, relaxation techniques, coping strategies based on sense of humour and positive thinking (Ostrowski, 2014).

Drawing conclusions from the findings reported in research and the literature, one could note that psychological resilience is a self-regulating mechanism that comprises cognitive (a belief about one's own competences, effectiveness), emotional (prevalence of positive emotions), and behavioural elements, i.e. seeking new ways to cope, focusing on a given task (Ogińska-Bulik \& Juczyński, 2008). Literary sources suggest that high psychological resilience and positive emotions as well as optimism, coherence, openness to experience, sense of self-effectiveness and self-worth and positive relations with others are positively correlated (Tugade \& Fredrickson, 2001, 2004, 2007; Tugade, Fredrickson, \& Barret, 2004; Connor, 2006; Semmer, 2006; Ogińska-Bulik \& Juczyński, 2008; Ong, Zautra, \& Reid, 2010; Waugh, Thompson, \& Gotlib, 2011). Psychological resilience might constitute a significant protective factor providing support in the psychological and social coping with an emotional crisis, a traumatic experience of cancer and the related mastectomy. Psychological resilience is a specific buffer that, when combined with positive emotions, allows one to overcome difficulties, find ways to solve problems, and change one's perspective on the situation (Tugade \& Fredrickson, 2004; Connor, 2006; Gillman et al., 2015). High psychological resilience is also related to a higher probability of post-traumatic growth (Fredrickson \& Tugade, 2004; Felcyn-Koczewska \& Ogińska-Bulik, 2011), including in women who have undergone mastectomy (Ogińska-Bulik, 2010). In the study conducted by Zemore and Shep- el (1989), as well as studies carried out by Cordova et al. (2001), results regarding closer interpersonal relations, appreciation of life and spiritual transformation were noted to be higher in a group of postmastectomy female participants compared to a group consisting of healthy ones. As noted by OgińskaBulik (2011), after experiencing trauma due to mastectomy, psychologically resilient women manifested positive changes compared to the control group, particularly with regard to self-perception and optimistic approach to life, as well as higher capacity to mobilise oneself in the face of adversity.

Psychological resilience proved to be positively correlated with acceptance of the disease and coping with negative emotions, while it was negatively correlated with being consumed by anxiety and helplessness. Additionally, the 'personal competences to cope and negative emotion tolerance' factor was proved to be particularly important for adapting to a disease. Possibly, determination and seeing the disease as a challenge, which is characteristic for highly resilient individuals, have an impact on one perceiving one's own physicality more in the categories of own health and less in the category of attractiveness (Wallace, Harcourt, Rumsey, \& Foot, 2007). In a study conducted by McGrath, Wiggin, and Caron (2009), psychological resilience was proved to be negatively correlated with dissatisfaction with one's own body in healthy young women. The experienced stress, negative experiences or traumatic experience (e.g., cancer) may contribute to the development of traits that form psychological resilience. It is congruent with the transactional approach to psychological resilience, according to which the individual and the environment mutually affect each other. This is confirmed in Japanese research of Ishibashi and Ueda (2003), who by means of reviewing literature on available studies on the development of psychological resilience in teenagers suffering from cancer concluded that negative experiences may also promote psychological resilience.

As suggested by the results of the above-presented studies, people with higher psychological resilience are characterised by a more positive emotionality, which is related to more positive relations with others. Moreover, psychological resilience is also correlated with greater openness and a more active search for solutions and more effective stress coping strategies (Fredrickson \& Tugade, 2004; Levine, Eckhardt, \& Targ, 2005; Felcyn-Koczewska \& Ogińska-Bulik, 2011), as well as coping with social pressure regarding appearance-related requirements (Choate, 2005; Fradelos et al., 2017).

When summarising the presented review of studies and theories explaining the psychological functioning of post-mastectomy women, one should also note the significance of the factor of time since mastectomy in a given female participant for her body
Psychological resilience and body image after mastectomy 
Bernadetta Izydorczyk, Anna

Kwapniewska, Sebastian Lizińczyk, Katarzyna SitnikWarchulska image and the level of psychological resilience. In the selected studies it is noted that after a year since mastectomy, $25.00-40.00 \%$ of the patients experience particularly severe stress and fear of a cancer relapse (Herschbach et al., 2004; Ogińska-Bulik, 2010). In a study on 142 women suffering from breast cancer who completed treatment and did not manifest cancer progression, Cordova et al. (2000) diagnosed as many as $8.50 \%$ of the women with a post-traumatic stress syndrome, whereas in Polish studies (Widera, Juczyński, \& Popiela, 2003), the intensity of avoidance, arousal and intrusion (which are the main symptoms of post-traumatic stress disorder) manifested by women diagnosed with breast cancer was similar to that observed in rape victims and individuals formerly kept as prisoners. Furthermore, Głębocka (2009) indicated that the formation of the body image is largely affected by social criticism, which may specifically affect post-mastectomy women, who are particularly sensitive to all comments from other people, as evidenced by Krok and Kubiec (2013). Moreover, individuals after breast reconstruction perceived the quality of their lives to be higher and felt more attractive (Tykkä et al., 2002), suggesting that one's body image was undervalued after mastectomy. The subject of the study by the authors of the article is related to the presented brief review of studies described in the literature, which provide a description of unequivocal findings on further investigation of the factors describing the specificity of changes in the body image and the specificity of protective factors (psychological resilience) in women in various stages after mastectomy. Since the findings presented in the literature are inconclusive, the issue ought to be further examined in subsequent populations of patients to ensure that the subject of this article is thoroughly analysed, as it has high application importance during treatment.

The authors of this article undertook the research problem of measuring variables that would allow them to provide a more in-depth description of the significance of both the body image and psychological resilience in a group of 119 Polish post-mastectomy women suffering from breast cancer. At the same time, a control group consisting of healthy women was included in the study to allow the discussed variables to be compared in both study populations. Despite their potentially high significance for explaining and determining the direction in treatment of breast cancer patients, few studies of this kind are available in the source material from the past ten years.

\section{RESEARCH OBJECTIVES AND QUESTIONS}

The study aimed to investigate specific intra-group differences regarding the body image and psychologi- cal resilience in a group of post-mastectomy women diagnosed with breast cancer depending on the time since mastectomy. Given the dynamics of psychological changes that take place when one reacts to a difficult situation (in this case, the surgical procedure of mastectomy), two development phases of the said adaptive reaction were taken into account. Analysis of the results of many contemporary studies indicates that sex and the length of time since the traumatic event (such as surgery ending with the partial or total loss of the bodily organ) are significant criteria in differentiating forecasts in the recovery process, that is, the development of negative health effects or the development of posttraumatic growth (Janssens \& Vandeloo, 2009; Vishnevsky, Cann, Calhoun, Tedeschi, \& Demakis, 2010). Some studies suggest that these difficulties may subside and remain relatively stable after about two years. The time since the traumatic event had a clear impact on the acceptance of the disease, because a high level of this variable was present in women who had reconciled with the disease for up to 2 years after surgery (Stanton, DanoffBurg, \& Huggins, 2002; Fingeret, Teo, \& Epner, 2014). The first phase of the adaptive reaction covered the time of the said reaction between the time of surgery and 2 years after mastectomy. The second phase of the adaptive reaction covered the time two years after the mastectomy procedure and the study. The twoyear period was selected as the criterion for classifying the study participants into two groups, as after such a period the process of psychological adaptive changes related to an acute phase of the response to the traumatic experience usually comes to an end following a specific 'mourning period' after losing the discussed organ (either entirely or partially).

Given the above, the following research questions were formulated:

1. What are the characteristics of the resilience variable and its components in the group of women after mastectomy and the control group?

2. Do post-mastectomy women differ from healthy women forming the control group in terms of their body image (and if so, to what extent)?

3. What are the characteristics of the resilience variable and its components in the group of women less than two years after mastectomy and women who underwent mastectomy over two years before the study?

4. Is the body image different in the post-mastectomy women less than two years after mastectomy compared to women who underwent mastectomy over two years before the study (and if so, in what way)?

\section{OPERATIONALISATION OF VARIABLES}

Two main variables were distinguished in the research model. 
Psychological resilience - a variable describing the set of skills allowing one to cope in severely stressful situation in a flexible and effective manner, which is manifested as the capacity to evoke positive emotions (optimism and the capacity to mobilise oneself, openness to new experiences and humour) and the capacity to detach from negative experiences (perseverance and determination, capacity to cope with negative emotions and tolerance for failure).

The second variable was defined as the body image. It is a variable describing a set of emotions, thoughts, beliefs and behaviours related to perception of and the attitude to one's own body. This variable is complex and comprises the following constituents:

1. Dissatisfaction with the body - a variable determining the level of negative emotions with regard to one's own body, the level of discomfort experienced in relation to one's own body and appearance (Brytek-Matera \& Probst, 2014).

2. Experiencing the body - a variable determining the difficulty of identifying one's own physical and emotional states, as well as the difficulty of experiencing the bond with one's own body as part of the Self, related to the feeling of anxiety and lack of control over the body (Brytek-Matera \& Probst, 2014).

3. Negative perception of the body - a variable determining the tendency to perceive negatively the size of one's own body and its particular parts (Mirucka, 2005; Brytek-Matera \& Probst, 2014).

4. Self-assessment of the body - a variable determining the level of general satisfaction with one's own body, its shape, appearance and weight (Mirucka, 2005).

5. Feelings related to intimate relationships - a variable determining the level of satisfaction with interpersonal physical contact involving corporeality and the emotional sphere (Mirucka, 2005).

6. Eating behaviour and weight control - a variable determining the positive non-restrictive approach to eating and body weight. It shows the absence of a tendency to excessive weight control and excessive focus on eating (Mirucka, 2005; Brytek-Matera \& Probst, 2014).

7. Behaviour towards the external appearance a variable determining the extent to which one's femininity was exposed by means of clothes or makeup, as well as the level of acceptance of oneself as a woman (Mirucka, 2005; Brytek-Matera \& Probst, 2014).

\section{PARTICIPANTS AND PROCEDURE}

\section{MATERIAL AND METHODS}

In order to answer the formulated research questions, three scales were applied, namely, the Resilience Measurement Scale (Skala Pomiaru Prężności, SPP-25) developed by Ogińska-Bulik and Juczyński (2008) to measure the variability of psychological resilience, the Body Attitude Test (BAT) developed by Probst, Van Coppenolle and Vandereycken (in a Polish version by Brytek-Matera, 2014), and Probst's Physical Self-Inventory (the Body Self Questionnaire developed by Mirucka, 2005) for the measurement of the body image variable. The Resilience Measurement Scale [SPP-25] is characterised by satisfactory psychometric properties (the Cronbach $\alpha$ for the entire scale was .89 , whereas for the individual subscales Cronbach's $\alpha$ ranged from .67 to .75). Test-retest reliability measured after four weeks was .85 , which means that resilience is highly reliable (Ogińska-Bulik \& Juczyński, 2008). The Body Attitude Test (BAT) was used for measuring the variability of the body image. The Polish version of this questionnaire has satisfactory psychometric properties. Reliability measured by Cronbach's $\alpha$ for the entire scale ranged from .85 to .90 , while individual subscales (excluding 2 other questions) ranged from .81 to .92 (Brytek-Matera \& Probst, 2014). The higher the result, the worse is the perception of one's own body. The questionnaire comprises three subscales, namely, general dissatisfaction; lack of familiarity with the body; and negative appreciation of body size (Brytek-Matera \& Probst, 2014). In this research, in order to measure the variables of the body image, the authors used the Body Self Questionnaire (Kwestionariusz fa Cielesnego, further referred to as the BSQ) developed by Mirucka (2005).

The said scale comprises 41 questions assessed on a 7-item scale from 0 (completely disagree) to 6 (completely agree) or 6 (completely disagree) to 0 (completely agree) in the case of inverted questions. The scale provides for the measurement of the general rate of the BSQ. The higher the score, the stronger is body self (Mirucka, 2005). The scale has satisfactory psychometric properties. For the entire scale, the rate for reliability for the Cronbach $\alpha$ is .93 , whereas in the case of individual subscales it ranges from .74 to .89 .

\section{CHARACTERISTICS OF THE STUDY GROUP}

Purposive sampling was used in selecting the study group participants. The criteria for inclusion in the clinical group were: sex (female), breast cancer diagnosis and completed mastectomy. In the control group, the main selection criteria were: sex (female), absence of breast cancer diagnosis, no history of cancer and no treatment due to breast cancer. 219 women were examined in total, including 120 post-mastectomy women diagnosed with breast cancer (clinical group), and 99 healthy female participants (women not diagnosed with breast cancer who did not undergo mastectomy and were not treated due to cancer), who formed the control group.
Psychological resilience and body image after mastectomy 
Bernadetta Izydorczyk, Anna

Kwapniewska, Sebastian Lizińczyk, Katarzyna SitnikWarchulska
SOCIAL-DEMOGRAPHIC CHARACTERISTICS OF THE CLINICAL GROUP AND THE CONTROL GROUP PARTICIPANTS (COMPARATIVE ANALYSIS)

In accordance with the adopted research procedure and the set objectives, the same demographic criteria were used to select study participants for the two groups. These criteria were their age and socialdemographic data (residential environment, marital status and education). In Table 1 a comparison of the social-demographic data is presented, which shows the similarities occurring between the clinical group and the control group.

The clinical group participants and the control group participants did not prove to differ in terms

Table 1

Socio-demographic characteristics of the clinical group participants $(n=120)$ and the control group participants $(n=99)$

\begin{tabular}{|c|c|c|}
\hline Socio-demographic variables & $\begin{array}{l}\text { Clinical } \\
\text { group }\end{array}$ & $\begin{array}{l}\text { Control } \\
\text { group }\end{array}$ \\
\hline Age $^{*}$ & $\begin{array}{c}55.90 \\
(11.74)\end{array}$ & $\begin{array}{c}54.40 \\
(12.07)\end{array}$ \\
\hline \multicolumn{3}{|l|}{ Residential environment * * } \\
\hline $\begin{array}{l}\text { Town (population below } \\
50,000 \text { people) }\end{array}$ & $14.20 \%$ & $18.20 \%$ \\
\hline $\begin{array}{l}\text { Town (population } \\
50,000-100,000 \text { people) }\end{array}$ & $24.20 \%$ & $27.10 \%$ \\
\hline $\begin{array}{l}\text { City (population } \\
100,000-200,000 \text { people) }\end{array}$ & $33.30 \%$ & $32.50 \%$ \\
\hline $\begin{array}{l}\text { City (population } \\
\text { over } 200,000 \text { people) }\end{array}$ & $28.30 \%$ & $22.20 \%$ \\
\hline \multicolumn{3}{|l|}{ Marital status ${ }^{* *}$} \\
\hline Currently single & $10.00 \%$ & $14.10 \%$ \\
\hline Married & $62.50 \%$ & $68.70 \%$ \\
\hline In a romantic relationship & $1.70 \%$ & $4.10 \%$ \\
\hline $\begin{array}{l}\text { Divorced/currently } \\
\text { separated }\end{array}$ & $5.80 \%$ & $3.00 \%$ \\
\hline Widowed & $20.00 \%$ & $10.10 \%$ \\
\hline \multicolumn{3}{|l|}{ Education** } \\
\hline Lower secondary or primary & $7.50 \%$ & $4.00 \%$ \\
\hline Basic & $10.00 \%$ & $8.50 \%$ \\
\hline $\begin{array}{l}\text { Upper secondary (including } \\
\text { post-secondary) }\end{array}$ & $45.30 \%$ & $35.80 \%$ \\
\hline Higher & $37.20 \%$ & $51.70 \%$ \\
\hline
\end{tabular}

Note. ${ }^{*}$ As a mean and standard deviation. ${ }^{*}$ As a percentage distribution of variables in the clinical group. of the results concerning their social-demographic characteristics concerning age, residential environment, marital status and education. All the participants were at a similar age (ranging from 54 to 55 years), while a vast majority had upper secondary or higher education. Both groups' participants were mostly married and resided in a similar environment both in towns and cities. Characteristics of the clinical group participants regarding the time since mastectomy and the type of breast reconstruction surgery are presented in Table 2 .

The study was conducted in the years 2016-2017 on a group of female inpatients at two metropolitan oncological hospitals in southern Poland and female participants of the Federation of Polish Post-Mastectomy "Amazons" Clubs from two cities in southern Poland as well. All women took part in the study upon giving their prior consent and were informed of the anonymous character of the study, the results of which were intended for scientific purposes only. All the research procedures were performed in line with the Helsinki Declaration of 1964 as further amended with regard to principles for medical research involving humans.

\section{RESULTS}

The study results were statistically analysed using the IBM SPSS Statistics software v.23. Due to the ab-

Table 2

Characteristics of the clinical group participants $(n=120)$ regarding indicators describing the time since and the type of mastectomy procedure $(n=120)$

\begin{tabular}{cc}
\hline Breast cancer information & $\begin{array}{c}\text { Clinical } \\
\text { group }\end{array}$ \\
\hline
\end{tabular}

Breast prosthesis*

Breast prosthesis in use

No breast prosthesis in use

$40.80 \%$

Breast reconstruction *

Breast reconstruction procedure completed

Breast reconstruction procedure not performed

Time since the surgery*

Less than 2 years

Over 2 years

Type of procedure*

Total mastectomy

Partial mastectomy $35.80 \%$ Note. ${ }^{*}$ As a percentage distribution of variables in the clinical group. 
sence of the normal distribution in all variables, studied differences between the groups were measured using the non-parametric Mann-Whitney $U$ test for both groups. Firstly, the clinical group was compared to the control group, and then comparisons within the clinical groups were performed by dividing the participants according to the time since mastectomy (either less than or more than 2 years after the procedure). In order to make the analysed results clearer, the group consisting of post-mastectomy women up to 2 years after mastectomy is referred to as group 1, whereas the group of women who had undergone mastectomy over 2 years before the study was called group 2. The level of statistical significance was set at $p<.05$.

An analysis of the study results regarding the comparison of the average intensity of psychological resilience in the clinical and the control groups revealed no differences between the two groups. Post-mastectomy women are characterised by a similar intensity of psychological resilience as that observed in healthy women. The above data are presented in Table 3.

As shown in average values presented in Table 3, psychological resilience is not significantly different between the control group and the clinical group in terms of any constituent of the investigated variable. The results of the statistical analysis suggest that psychological resilience does not change under the influence of the extremely difficult experience of cancer and the related mastectomy procedure. In order to conduct a more in-depth statistical analysis of the differences between participants of the clinical group and the control group, the statistical significance of the said differences was measures with regard to psychological resilience. The clinical group was divided according to the time since mastectomy (group 1
- up to 2 years after mastectomy; group 2 - over 2 years after mastectomy). The results of the statistical analysis of the above-mentioned research area are presented in Tables 4 and 5 .

The statistical analyses indicated significant differences between the control group and the clinical group (up to 2 years after mastectomy). Women up to 2 years after mastectomy showed a slightly greater general psychological resilience than healthy women, as in the case of two constituents of the variable described in Table 4, i.e. perseverance and determination, and coping with negative emotions. Here, women up to 2 years after mastectomy also manifested a higher level of coping with frustration, negative emotions and a higher level of perseverance in relation to their behaviour. Furthermore, women over 2 years after mastectomy were compared to healthy women (control group). Results of the statistical analysis are presented in Table 5 .

The conducted statistical analysis comparing the clinical groups (group 1 - up to 2 years after mastectomy; group 2 - over 2 years after mastectomy) and the control group allowed for the following conclusions to be drawn.

General psychological resilience is significantly different between group 1 and the control group (it is notably higher in group 1), while it is not different between group 2 and the control group. Likewise, in the case of two variables, namely, perseverance and determination, and coping with negative emotions (variable components of the dimension 'capacity to detach from difficult situations'), a significant difference was observed only between group 1 and the control group (in both cases a higher level was observed in group 1). In other cases, the differences

Table 3

Comparison of raw results regarding the indicators of the 'psychological resilience' variable between post-mastectomy women (clinical group $n=120)$ and the control group participants $(n=99)$. The Mann-Whitney $U$ test, Me and $S D$ for both groups

\begin{tabular}{|c|c|c|c|c|c|c|}
\hline \multirow[t]{2}{*}{ Psychological resilience } & \multicolumn{2}{|c|}{ Control group } & \multicolumn{2}{|c|}{ Clinical group } & \multirow[t]{2}{*}{$U$} & \multirow[t]{2}{*}{$p$} \\
\hline & $M e$ & $S D$ & Me & $S D$ & & \\
\hline General psychological resilience & 70.00 & 12.09 & 73.00 & 13.96 & 5574.50 & .433 \\
\hline \multicolumn{7}{|c|}{ Capacity to evoke positive emotions } \\
\hline $\begin{array}{l}\text { Optimism and capacity to } \\
\text { mobilise oneself }\end{array}$ & 13.00 & 3.07 & 13.00 & 3.45 & 5726.00 & .645 \\
\hline $\begin{array}{l}\text { Openness to new experiences } \\
\text { and humour }\end{array}$ & 16.00 & 2.52 & 16.00 & 2.99 & 5823.00 & .800 \\
\hline \multicolumn{7}{|c|}{ Capacity to detach from difficult situations } \\
\hline Perseverance and determination & 15.00 & 3.35 & 16.00 & 3.00 & 5165.50 & .095 \\
\hline Coping with negative emotions & 13.00 & 3.22 & 14.00 & 3.41 & 5568.50 & .423 \\
\hline Tolerance for failure & 15.00 & 2.60 & 14.50 & 3.10 & 5909.50 & .948 \\
\hline
\end{tabular}


proved statistically insignificant. Therefore, it can be stated that a short period of time after mastectomy is significantly related to a higher level of both psychological resilience and better coping with negative emotions. The statistical analysis of the study results also pertained to the measurement of the significance level regarding differences in the body image between post-mastectomy women and healthy women. Here, differences were expected to occur between the clini- cal group participants and the control group participants. The said data are presented in Table 6.

The comparative analysis of average results suggested several significant differences existing between healthy women and post-mastectomy women with regard to experiencing the body - the clinical group participants manifested a higher level of this variable compared to the control group. Feelings related to intimate relationships and self-assessment of
Bernadetta Izydorczyk, Anna Kwapniewska, Sebastian Lizińczyk, Katarzyna SitnikWarchulska

Table 4

Comparison of raw results regarding indicators of the psychological resilience variable (selected dimensions) between women up to 2 years after mastectomy (group 1, $n=64$ ) and the control group participants $(n=99)$. The Mann-Whitney $U$ test, Me and SD for both groups

\begin{tabular}{|c|c|c|c|c|c|c|}
\hline \multirow[t]{2}{*}{ Psychological resilience } & \multicolumn{2}{|c|}{ Control group } & \multicolumn{2}{|c|}{$\begin{array}{c}\text { Group } 1 \\
\text { (up to } 2 \text { years } \\
\text { after mastectomy) }\end{array}$} & \multirow[t]{2}{*}{$U$} & \multirow[t]{2}{*}{$p$} \\
\hline & $M e$ & $S D$ & Me & $S D$ & & \\
\hline General psychological resilience & 70.00 & 12.09 & 74.50 & 13.07 & 2609.00 & .057 \\
\hline \multicolumn{7}{|c|}{ Capacity to evoke positive emotions } \\
\hline $\begin{array}{l}\text { Optimism and capacity to } \\
\text { mobilise oneself }\end{array}$ & 13.00 & 3.07 & 14.00 & 3.28 & 2891.50 & .345 \\
\hline $\begin{array}{l}\text { Openness to new experiences } \\
\text { and humour }\end{array}$ & 16.00 & 2.52 & 16.00 & 3.00 & 2940.00 & .434 \\
\hline \multicolumn{7}{|c|}{ Capacity to detach from difficult situations } \\
\hline Perseverance and determination & 15.00 & 3.35 & 16.00 & 2.86 & 2428.50 & .012 \\
\hline Coping with negative emotions & 13.00 & 3.22 & 15.00 & 3.17 & 2573.00 & .042 \\
\hline Tolerance for failure & 15.00 & 2.60 & 15.00 & 2.81 & 2835.00 & .254 \\
\hline
\end{tabular}

Table 5

Comparison of raw results regarding the indicators of the 'psychological resilience' variable (selected dimensions) between women over 2 years after mastectomy (group 2, $n=56$ ) and the control group participants $(n=99)$. The Mann-Whitney $U$ test, Me and SD for both groups

\begin{tabular}{|c|c|c|c|c|c|c|}
\hline \multirow[t]{2}{*}{ Psychological resilience } & \multicolumn{2}{|c|}{ Control group } & \multicolumn{2}{|c|}{$\begin{array}{l}\text { Group } 2 \text { (clinical } \\
\text { group over } 2 \text { after } \\
\text { mastectomy) }\end{array}$} & \multirow[t]{2}{*}{$U$} & \multirow[t]{2}{*}{$p$} \\
\hline & $M e$ & $S D$ & $M e$ & $S D$ & & \\
\hline General psychological resilience & 70.00 & 12.09 & 69.50 & 14.49 & 2578.50 & .471 \\
\hline \multicolumn{7}{|c|}{ Capacity to evoke positive emotions } \\
\hline $\begin{array}{l}\text { Optimism and capacity to } \\
\text { mobilise oneself }\end{array}$ & 13.00 & 3.07 & 13.00 & 3.65 & 2709.50 & .815 \\
\hline $\begin{array}{l}\text { Openness to new experiences } \\
\text { and humour }\end{array}$ & 16.00 & 2.52 & 15.50 & 2.92 & 2427.00 & .195 \\
\hline \multicolumn{7}{|c|}{ Capacity to detach from difficult situations } \\
\hline Perseverance and determination & 15.00 & 3.35 & 14.50 & 3.10 & 2737.00 & .896 \\
\hline Coping with negative emotions & 13.00 & 3.22 & 13.00 & 3.51 & 2548.50 & .402 \\
\hline Tolerance for failure & 15.00 & 2.60 & 14.00 & 3.31 & 2408.50 & .172 \\
\hline
\end{tabular}


Table 6

Comparison of raw results for the indicators of the 'body image' variable (cognitive-emotional dimension and body-oriented behaviour) between post-mastectomy women (clinical group $n=120$ ) and control group participants $(n=99)$. The Mann-Whitney $U$ test, Me and SD for both groups

\begin{tabular}{|c|c|c|c|c|c|c|}
\hline \multirow[t]{2}{*}{ Body image } & \multicolumn{2}{|c|}{ Control group } & \multicolumn{2}{|c|}{ Clinical group } & \multirow[t]{2}{*}{$U$} & \multirow[t]{2}{*}{$p$} \\
\hline & $M e$ & $S D$ & Me & $S D$ & & \\
\hline \multicolumn{7}{|c|}{ Cognitive-emotional dimension } \\
\hline $\begin{array}{l}\text { General dissatisfaction with the } \\
\text { body }\end{array}$ & 28.00 & 15.25 & 28.00 & 14.01 & 5386.50 & .235 \\
\hline Dissatisfaction with the body & 6.00 & 3.49 & 6.00 & 3.81 & 5780.00 & .731 \\
\hline Experiencing the body & 7.00 & 5.51 & 10.00 & 4.95 & 4543.50 & .003 \\
\hline Perceiving the body & 10.00 & 7.26 & 9.00 & 6.84 & 5827.50 & .809 \\
\hline Self-assessment of the body & 55.00 & 14.08 & 51.00 & 14.43 & 4993.50 & .042 \\
\hline $\begin{array}{l}\text { Feelings related to intimate } \\
\text { relationships }\end{array}$ & 56.00 & 12.04 & 49.00 & 13.07 & 4214.00 & .001 \\
\hline \multicolumn{7}{|c|}{ Body-oriented behaviour } \\
\hline $\begin{array}{l}\text { Eating behaviour and weight } \\
\text { control }\end{array}$ & 39.00 & 9.84 & 36.00 & 10.14 & 4828.50 & .017 \\
\hline Appearance-oriented behaviour & 20.00 & 6.35 & 19.00 & 6.27 & 5531.00 & .380 \\
\hline
\end{tabular}

the body - post-mastectomy women proved to experience intimate relationships less intensely compared to healthy women.

The findings suggest that the clinical group participants experience a greater difficulty to identity their own physical and emotional states, and experience a weaker bond with their own body as part of the Self, which is most often related to feelings of fear and a lack of control over the body. Post-mastectomy women are also characterised by a significantly lower self-assessment of the body; hence, they are less satisfied with their own body (its shape, appearance, weight) and notice a greater disparity between what they look like and what they would like to look like. Moreover, significant differences can be seen also with regard to feelings related to intimate relationships. It can be concluded that the said group of women are characterised by more intense negative feelings related to intimate relationships and experience less satisfaction with physical contact with another person, which involves corporeality and the emotional sphere.

\section{CHARACTERISTICS OF THE INTRA-GROUP DIFFERENCES REGARDING PSYCHOLOGICAL RESILIENCE BETWEEN POST-MASTECTOMY WOMEN UP TO 2 YEARS (GROUP 1) AND OVER 2 YEARS (GROUP 2) AFTER THE PROCEDURE}

In the final stage of the statistical analysis, in line with the research questions that were put forward, it was decided that the possible existence of differences with regard to psychological resilience and its individual dimensions should be examined among the clinical group participants up to two years after the procedure (group 1) and in women who had undergone the procedure over 2 years before the study (group 2). As suggested by results presented in Table 7 , the groups are significantly different in terms of their general psychological resilience $(U=1383.00$, $p=.031$ ). Group 1 participants are characterised by a substantially higher psychological resilience and its three constituents: perseverance and determination ( $U=1371.00, p=.026)$, coping with negative emotions $(U=1310.00, p=.011)$ and tolerance for failure $(U=1386.00, p=.032)$. Therefore, women shortly after the surgery are more psychologically resilient particularly with regard to their capacity to detach from difficult situations, while no significant differences were manifested in terms of the capacity to evoke positive emotions in oneself.

The comparative analysis of average results in clinical groups 1 and 2 shows significant differences between post-mastectomy women up to 2 years and over 2 years after mastectomy regarding the following variables: general psychological resilience (higher among women up to 2 years after mastectomy) and the constituent of psychological resilience defined as the capacity to detach from difficult situations. A significant rise in all variables forming the above-mentioned capacity manifested in women up to 2 years after mastectomy.
Psychological resilience and body image after mastectomy 
Table 7

Comparison of raw results for the indicators of the 'psychological resilience' variable (selected dimensions) between women up to 2 years after mastectomy (group 1, $n=64$ ) and women over 2 years after mastectomy (group 2, $n=56$ ). The Mann-Whitney $U$ test, Me and SD for both groups

\begin{tabular}{|c|c|c|c|c|c|c|}
\hline \multirow[t]{2}{*}{ Psychological resilience } & \multicolumn{2}{|c|}{$\begin{array}{c}\text { Group } 1 \\
\text { (up to } 2 \text { years after } \\
\text { mastectomy) }\end{array}$} & \multicolumn{2}{|c|}{$\begin{array}{c}\text { Group } 2 \\
\text { (over } 2 \text { years after } \\
\text { mastectomy) }\end{array}$} & \multirow[t]{2}{*}{$U$} & \multirow[t]{2}{*}{$p$} \\
\hline & Me & $S D$ & Me & $S D$ & & \\
\hline General psychological resilience & 74.50 & 13.07 & 69.50 & 14.49 & 1383.00 & .031 \\
\hline \multicolumn{7}{|c|}{ Capacity to evoke positive emotions } \\
\hline $\begin{array}{l}\text { Optimism and capacity to } \\
\text { mobilise oneself }\end{array}$ & 14.00 & 3.28 & 13.00 & 3.65 & 1621.00 & .366 \\
\hline $\begin{array}{l}\text { Openness to new experiences } \\
\text { and humour }\end{array}$ & 16.00 & 3.00 & 15.50 & 2.92 & 1475.50 & .094 \\
\hline \multicolumn{7}{|c|}{ Capacity to detach from difficult situations } \\
\hline Perseverance and determination & 16.00 & 2.80 & 14.50 & 3.10 & 1371.00 & .026 \\
\hline Coping with negative emotions & 15.00 & 3.17 & 13.00 & 3.52 & 1310.00 & .011 \\
\hline Tolerance for failure & 15.00 & 2.81 & 14.00 & 3.31 & 1386.00 & .032 \\
\hline
\end{tabular}

Nonetheless, a significant difference between the examined clinical groups was not found only with regard to the capacity to evoke positive emotions. This might suggest that women shortly after mastectomy can make use of their own capabilities to distance themselves from many negative experiences related to the procedure, while they are unable to develop positive emotions equally fast. In this regard, they are similar to women who underwent mastectomy earlier and who were experiencing a complete or partial loss of a breast for a longer time.

To conclude, the obtained results might suggest that the women's experiences related to the procedure of the mastectomy and the consequences of further post-operative functioning may manifest characteristics of depressive syndromes (e.g. sadness due to compromised health and permanent loss of an organ). However, the findings indicate that resilience becomes reduced with time after the procedure, followed by a decreased tolerance for failure and hindered coping with negative emotions.

A similar comparative analysis is presented in Table 8, showing the comparison of raw results for rates of the 'body image' variable between the participants of group 1 (up to 2 years after mastectomy) and group 2 (over 2 years after mastectomy).

\section{CHARACTERISTICS OF INTRA-GROUP DIFFERENCES REGARDING THE BODY IMAGE AMONG POST-MASTECTOMY WOMEN}

The comparative analysis of the average intensity of constituents of the 'body image' variable in clinical groups 1 and 2 reveals no significant differences. The results proved that regardless of the time since the procedure, post-mastectomy women manifest a similar body image at emotional, cognitive and behavioural levels (Table 8 ). To conclude, the body image is a variable that changes not due to mastectomy but as a result of numerous other psychological factors. The body image does not change depending on the time since mastectomy and the damage to the body.

\section{DISCUSSION}

The statistical analysis of the results obtained in our study proved that there are some small yet significant differences in the verified constituents of the 'psychological resilience' variable between post-mastectomy women (regardless of the criterion of the time since mastectomy) and healthy women (control group). The absence of significant differences with regard to psychological resilience between the group of healthy women and post-mastectomy women was suggested in studies conducted by Ogińska-Bulik (2010, 2011). However, as for the comparison of the body image of healthy women and post-mastectomy women in our study and in studies by other authors, it should be noted that the absence of significant differences between post-mastectomy participants and healthy participants was also indicated by other researchers (Głębocka, 2009). What is more, authors of other studies note lower sense of attractiveness and higher dissatisfaction with one's own body among 
Table 8

Comparison of raw results for the indicators of the 'body image' variable (selected dimensions) between women up to 2 years after mastectomy (group 1, $n=64$ ) and women over 2 years after mastectomy (group 2, $n=56$ ).

The Mann-Whitney $U$ test, Me and SD for both groups

\begin{tabular}{|c|c|c|c|c|c|c|}
\hline \multirow[t]{2}{*}{ Body image } & \multicolumn{2}{|c|}{$\begin{array}{l}\text { Up to } 2 \text { years after } \\
\text { mastectomy }\end{array}$} & \multicolumn{2}{|c|}{$\begin{array}{l}\text { Over } 2 \text { years after } \\
\text { mastectomy }\end{array}$} & \multirow[t]{2}{*}{$U$} & \multirow[t]{2}{*}{$p$} \\
\hline & $M e$ & $S D$ & Me & $S D$ & & \\
\hline \multicolumn{7}{|c|}{ Cognitive-emotional dimension } \\
\hline $\begin{array}{l}\text { General dissatisfaction with the } \\
\text { body }\end{array}$ & 28.00 & 13.88 & 28.50 & 14.29 & 1767.50 & .897 \\
\hline Dissatisfaction with the body & 5.00 & 3.85 & 6.00 & 3.80 & 1662.00 & .492 \\
\hline Experiencing the body & 11.00 & 4.71 & 9.00 & 5.25 & 1703.00 & .639 \\
\hline Perceiving the body & 9.00 & 6.98 & 9.50 & 6.75 & 1775.00 & .929 \\
\hline Self-assessment of the body & 52.00 & 13.84 & 49.50 & 15.17 & 1674.00 & .535 \\
\hline $\begin{array}{l}\text { Feelings related to intimate } \\
\text { relationships }\end{array}$ & 50.00 & 11.45 & 47.00 & 14.72 & 1642.50 & .431 \\
\hline \multicolumn{7}{|c|}{ Body-oriented behaviour } \\
\hline $\begin{array}{l}\text { Eating behaviour and weight } \\
\text { control }\end{array}$ & 38.00 & 11.04 & 35.00 & 8.93 & 1435.00 & .060 \\
\hline Appearance-oriented behaviour & 19.50 & 5.87 & 19.00 & 6.76 & 1748.00 & .817 \\
\hline
\end{tabular}

post-mastectomy women (Życińska, 2005). One could ask, to what extent are the results of our study specific for the selected group of participants? It is worth further investigating this area of research (the body image of post-mastectomy women and its specificity) in subsequent populations of patients to further specify the course of the differences between the population of healthy women and post-mastectomy women. In the course of our study, when comparing post-mastectomy women with the control group participants regarding the intensity of psychological resilience, the clinical group participants up to 2 years after mastectomy manifested greater capacity to detach from difficult situations - capacity to mobilise oneself in the face of adversity, a higher level of perseverance and determination in action, and coping with negative emotions in the course of the disease and mastectomy. Here, it is worth considering to what extent the above results indicate that defence mechanisms were activated to fight cancer, leading to a growing tendency to detach from a difficult situation. It is worth considering to what extent the study results might suggest the post-traumatic development discussed in studies by other authors (FelcynKoczewska \& Ogińska-Bulik, 2010). When discussing the concept of post-traumatic development, Tedeschi and Calhoun (1998, 2006; Ogińska-Bulik, 2010) indicate that the highest number of positive changes appears from two weeks to two months following a difficult experience. Ogińska-Bulik (2010) cited data that stress the occurrence of post-traumatic development primarily in the early stage of cancer (Tedeschi, Park, \& Calhoun, 1998; Tedeschi \& Calhoun, 2006). Similar results were obtained also by Manne et al. (2004), suggesting that the post-traumatic growth occurred in patients eighteen months after being diagnosed and anticancer treatment started. After the difficult experience of cancer, psychological resilience and posttraumatic growth may facilitate coping with difficult, traumatic events when an adversity arises. When it comes to mastectomy, particular importance is given in the postoperative period to the capacity to detach from negative experiences by focusing on fighting the disease, being perseverant and determined to recover and to return to normal life, considering the disease a challenge and thus, manifesting tolerance for failure and negative emotions. This is consistent with Ogińska-Bulik's research (2011), which suggests that the 'personal competences to cope and negative emotion tolerance' factor was particularly important in adopting to breast cancer. In our study, similarly as in Ogińska-Bulik's study (2011), the capacity to evoke positive emotions proved of lesser importance. Possibly, coming to terms with the loss of a breast requires greater acceptance, tolerance and the capacity to cope with negative emotions than evoking positive emotions, optimism and humour does. The prevalence of negative emotions in the group of post-mastectomy women was proved also in a study by Krok and Kubiec (2013).

\section{Psychological resilience and body image after mastectomy}


Bernadetta Izydorczyk, Anna

Kwapniewska, Sebastian Lizińczyk, Katarzyna SitnikWarchulska
Our study did not show any significant differences in dissatisfaction with the body between the clinical group of post-mastectomy women and the control group. Nevertheless, one of the dimensions of general dissatisfaction with the body, namely, experiencing one's own body, proved to be significantly higher among post-mastectomy women. Perhaps, as a result of the severe interference in their physique and the life-threatening somatic disease they experienced, these women have a weaker bond with their bodies as part of the Self, and experience more fear or anxiety with regard to the body, which in a sense became a threat due to the disease. This is discussed by Leksowska, Jaworska and Gorczyca (2011), who claimed that most often, an individual suffering from cancer becomes more attentive to signals received from the body when symptoms appear, while in severe cases such persons acquire a compulsion to self-observe and tend to interpret them as anxiety-provoking stimuli indicating a threat, e.g. an exacerbation or a relapse (p. 246). It seems consistent with the position taken by Sakson-Obada (2009a, 2009b; Mirucka \& SaksonObada, 2013), stating that people who lived through trauma can experience disorders related to body identity, identification of their own emotions and physical condition or hindered reception of stimuli from the environment. However, the area concerned with experiencing one's own body in a person suffering from a chronic cancer, e.g. breast cancer, would require further examination, possibly using other methods. Moreover, the findings of this study proved that postmastectomy women are characterised by more negative feelings related to intimate relationships, which is related to lower satisfaction with physical contact and a sense of fear, anxiety, and shame in intimate relationships. A similar issue is indicated in the source literature (Sakson-Obada, 2009a, 2009b; Głębocka, 2009). The authors mention negative changes experienced by women with regard to the sex-related roles they used to fulfil, the so-called 'half woman complex', which manifests in a lowered sense of one's own attractiveness or reduced self-acceptance of oneself as a woman (Mika, 1991; Walden-Gałuszko, Majkowicz, Trojanowski, \& Trzebiatowska, 1994; Życińska, 2005). Many researchers also draw attention to side effects of cancer treatment that also have a significant effect on the quality of intimate contact between partners (Fobair et al., 2006; Sheppard \& Ely, 2008). This leads to a feeling of fear, shame, and self-consciousness in an intimate relationship, which in turn result in the unwillingness to show oneself naked to the partner and avoidance of intimate situations (Mroczek et al., 2012).

Post-mastectomy women were also characterised by a more restrictive approach to physical exercise, eating and weight control. One might assume that such an approach entails the willingness to live a healthier lifestyle following the experienced disease, as well as to improve one's own appearance and attractiveness, which might be a form of compensation for the incurred loss and is related to the willingness to regain one's femininity and sexual attractiveness. This result is quite surprising given the fact that post-mastectomy women and the control group did not differ in terms of behaviour aiming to improve the external appearance using clothes or makeup.

Based on the comparison of both clinical groups (group 1 comprising women up to 2 years after mastectomy and group 2 comprising women over 2 years after mastectomy) and the control group, it was proved that compared to the control group, women over 2 years after mastectomy manifested differences in all the verified constituents of the body image, i.e. experiencing the body, self-assessment of the body, feelings related to intimate relationships, eating behaviour and weight control. Whereas compared to the control group, post-mastectomy participants of group 1 showed differences only regarding two dimensions: experiencing the body and feelings related to intimate relationships. Women up to 2 years after mastectomy are thus characterised by more negative feelings in such intimate relationships and experience their own bodies more negatively. This indicates that shortly after surgery, women are focused more on the emotional sphere related to bodily sensations, and they also feel a similar level of self-consciousness and fear of intimate relationships as women later after mastectomy do. However, they are to a lesser degree engaged in a cognitive assessment of their own body, which is probably due to putting a greater focus on recovery and the former health condition than on physical attractiveness. For that very reason, they are also less likely to engage in more restrictive eating behaviours and weight control. Possibly, the behavioural aspect in group 2 is focused to a greater extent on rehabilitation and health-promoting behaviours than those aiming to improve their physique.

Negative feelings related to intimate relationships and avoidance of such contact can be linked in this group to a greater extent to ailments related to cancer and treatment than to a negative self-assessment of one's body and reduced sense of attractiveness. Attractiveness and femininity become possibly far more important several years after the surgery, when a woman feels healthy, experiences no physical problems and starts comparing herself to women who did not undergo such procedure. The tendency to focus largely on one's own health and recovery after the disease is depicted in a study by Wallace et al. (2007), which investigated girls aged 14-19 years who had completed cancer treatment within the previous 2 years. The said study proved that girls tended to attach little significance to their own attractiveness and focused to a greater extent on returning to their 'normal' appearance as a sign of good health. They were able to re-interpret defects of their appearance such as surgical scars in a more positive 
way, e.g. as a sign of their strength or a symbol of a successfully overcome adversity. Perhaps, a similar tendency might occur in women up to 2 years after mastectomy. However, this area requires more in-depth studies on populations of women suffering from breast cancer. Moreover, one should take into consideration the limitations of this research, which resulted partially from the inclusion of the body image variable, which was difficult to verify empirically. In the literature, the said variable is defined multidimensionally in relation to the model adopted by a given researcher (the psychodynamic approach, the cognitive-behavioural approach). The wide range of body image definitions and measurement methods requires this area to be further examined using uniform criteria for measuring the said variable. Hence, in the research presented in this article body image was defined in a multidimensional way with regard to the source material and acknowledged psychological theories (the cognitive paradigm).

\section{CONCLUSIONS}

1. No significant differences were found with regard to the time since mastectomy (between women over 2 years and up to 2 years after the procedure) concerning the specificity of the overall body image expressed by these participants.

2. Significant differences were found between healthy women and post-mastectomy women regarding self-assessment of the body. Post-mastectomy patients proved to have a significantly poorer self-assessment of the body compared to healthy women and, consequently, more restrictive eating behaviours and weight control employed with the aim of improving their appearance. The women from the clinical group are thus characterised by a more negative body image compared to the control group.

3. The women from the clinical group who had undergone mastectomy up to 2 years before the study seemed more focused on mobilising their resources necessary to adapt to new conditions and to restore balance after the difficult experience compared to women who had undergone mastectomy over 2 years before the study. The former are characterised by a higher degree of psychological resilience, higher perseverance and determination in action. They also better cope with experienced failure and negative emotions, which proves that they have a greater capacity to detach from difficult situations.

4. The greater mobilisation of resources necessary to adapt to new conditions and to restore balance after a difficult experience in women up to 2 years after mastectomy may require consideration and application of psychological support from the very beginning of treatment, possibly with the use of elements of psychotherapy in order to strengthen the resources of a woman suffering from breast cancer and prevent her capacity to cope from being exhausted, which could hinder coping with negative emotions and adapting to permanent disability.

\section{References}

Borucka, A. (2011). Koncepcja resilience. Podstawowe założenia i nurty badań [The concept of resilience. Main principles and research trends]. In W. Junik (Ed.), Teoria - badania - praktyka. Resilience [Resilience - theory and research] (pp. 11-28). Warszawa: Wyd. Edukacyjne PARPAMEDIA.

Borucka, A. (2011). Koncepcja resilience. Podstawowe założenia i nurty badań [The concept of res ilience: basic assumptions and research trends]. In W. Junik (Ed.), Resilience - teoria, badania, praktyka (pp. 11-28). Warszawa: PARPAMEDIA.

Brytek-Matera, A., \& Probst, M. (2014). Psychometric properties of the Polish version of the Body Attitude Test. Archives of Psychiatry and Psychotherapy, 1, 39-46.

Choate, L. H. (2005). Toward a theoretical model of women's body image resilience. Journal of Counseling \& Development, 83, 320-330.

Connor, K. M. (2006). Assessment of resilience in the aftermath of trauma. Journal of Clinical Psychiatry, 67, 46-49.

Cordova, M. J., Cunningham, L. L., Carlson, C. R., \& Andrykowski, M. A. (2001). Posttraumatic growth following breast cancer: a controlled comparison study. Health Psychology, 20, 176-185.

Cordova, M. J., Studts, J. L., Hann, D. M., Jacobsen, P. B., \& Andrykowski, M. (2000). Symptom structure of PTSD following breast cancer. Journal of Traumatic Stress, 13, 301-319.

Dunn, L. B., Cooper, B. A., Neuhaus, J., West, C., Paul, S., Aouizerat, B., Abrams, G., Edrington, J., Hamolsky, D., \& Miaskowski, C. (2011). Identification of distinct depressive symptom trajectories in women following surgery for breast cancer. Health Psychology, 30, 683-692.

Falk Dahl, C. A., Reinertsen, K., Nesvold, I. L., Fosså, S. D., \& Dahl, A. (2010). A study of body image in long-term breast cancer survivors. Cancer, 116, 3549-3557.

Felcyn-Koczewska, M., \& Ogińska-Bulik, N. (2011). Rola prężności w rozwoju potraumatycznym osób $\mathrm{w}$ żałobie [The role of resilience in posttraumatic growth of persons in bereavement]. In L. Golińska \& E. Bielawska-Batorowicz (Eds.), Rodzina i praca $w$ warunkach kryzysu [Family and work in crisis conditions] (pp. 511-524). Łódź: Wydawnictwo UŁ.

Fingeret, M. C., Teo, I., \& Epner, D. E. (2014). Managing body image difficulties of adult cancer pa-
Psychological resilience and body image after mastectomy 
tients: Lessons from available research. Cancer, 120, 633-641.

Fobair, P., Stewart, S. L., Chang, S., D’Onofrio, C., Banks, P. J., \& Bloom, J. R. (2006). Body image and sexual problems in young women with breast cancer. Psycho-Oncology, 15, 579-594.

Folkman, S., \& Moskowitz, J. T. (2000). Positive affect and the other side of coping. American Psychologist, 55, 647-654. http://dx.doi.org/10.1037/0003066X.55.6.647

Bernadetta Izydorczyk, Anna

Kwapniewska, Sebastian Lizińczyk, Katarzyna SitnikWarchulska

Fradelos, E. C., Papathanasiou, I. V., Veneti, A., Daglas, A., Christodoulou, E., Zyga, S., \& Kourakos, M. (2017). Psychological Distress and Resilience in Women Diagnosed with Breast Cancer in Greece. Asian Pacific Journal of Cancer Prevention, 18, 2545-2550.

Fredrickson, B. L. (2004). The broaden-and-build theory of positive emotions. Philosophical Transactions of the Royal Society B: Biological Sciences, 359, 1367-1377.

Gillman, L., Adams, J., Covac, R., Kilcullen, A., House, A., \& Doyle C. (2015). Strategies to promote coping and resilience in oncology and palliative care nurses caring for adult patients with malignancy: a comprehensive systematic review. JBI Database of Systematic Reviews and Implementation Reports, 13, 131-204. https://doi.org/10.11124/jbisrir-2015-1898

Głębocka, A. (2009). Niezadowolenie z wygladu a rozpaczliwa kontrola wagi [Dissatisfaction with appearance and desperate weight control]. Kraków: Oficyna Wydawnicza Impuls.

Herschbach, P., Keller, M., Knight, L., Brandl, T., Huber, B., Henrich, G., \& Marten-Mittag, B. (2004). Psychological problems of cancer patients: cancer distress screening with a cancer-specific questionnaire. British Journal of Cancer, 91, 504-511.

Heszen, I., \& Sęk, H. (2007). Psychologia zdrowia [Health psychology]. Warszawa: PWN.

Ishibashi, A., \& Ueda, R. (2003). Resilience in adolescents with cancer. Japanese Journal of Health and Human Ecology, 69, 220-232.

Janssens, J. P., \& Vandeloo, M. (2009). Breast cancer: Direct and indirect risk factors related to age and lifestyle. Nowotwory, 59, 159-167.

Kozela, M., Stepaniak, U., \& Pająk, A. (2011). Membership in breast cancer peer-support organization (Amazons Club) and depression. Contemporary Oncology, 15, 55-58.

Krok, D., \& Kubiec, W. (2013). Dobrostan psychiczny i wizerunek ciała u kobiet po mastektomii i ich córek [Mental well-being and body image in post-mastectomy women and their daughters]. In D. Krok \& A. Bronowicka (Eds.), Jednostka i religia $w$ relacjach spotecznych [Individual and religion in social relations] (pp. 139-166). Opole: University of Opole.

Leksowska, A., Jaworska, I., \& Gorczyca, P. (2011). Choroba somatyczna jako wyzwanie adaptacyj- ne dla człowieka [Somatic disease as an adaptive, human challenge]. Folia Cardiologica Excerpta, 6, 244-248.

Levine, E. G., Eckhardt, J., \& Targ, E. (2005). Change in post-traumatic stress symptoms following psychosocial treatment for breast cancer. PsychoOncology, 14, 618-635.

Luthar, S. S. (2006). Resilience in development: A synthesis of research across five decades. In D. Cicchetti \& D. J. Cohen (Eds.), Developmental psychopathology: Risk, disorder, and adaptation (Vol. 2, pp. 739-795). Hoboken, NY: John Wiley.

Manne, S., Ostroff, J., Winkel, G., Goldstein, L., Fox, K., \& Grana, G. (2004). Posttraumatic growth after breast cancer: Patient, partner, and couple perspectives. Psychosomatic Medicine, 66, 442-454.

McGrath, R. J., Wiggin, J., \& Caron R. M. (2009). The relationship between resilience and body image in college women. The Internet Journal of Health, 10. Retrieved from http://scholars.unh. edu/hmp_facpub/15

Meder, J. (2014). Rak głównym zabójcą ludzi w XXI wieku. Narodowy Program Zwalczania Chorób Nowotworowych [Cancer as the leading killer of people in the 21st century: The National Programme for Combating Cancer]. In A. Potrykowska, Z. Strzelecki, J. Szymborski, \& J. Witkowski (Eds.), Zachorowalność i umieralność na nowotwory a sytuacja demograficzna Polski [Cancer morbidity and mortality and the demographic situation in Poland] (pp. 50-85). Warszawa: Rządowa Rada Ludnościowa.

Mirucka, B. (2005). Kwestionariusz Ja Cielesnego [Body Self Questionnaire]. Przegląd Psychologiczny, 48, 313-329.

Mirucka, B., \& Sakson-Obada O. (2013). Ja cielesne: od normy do zaburzeń [Body self: from sound health to disorders]. Sopot: Gdańskie Wydawnictwo Psychologiczne.

Mroczek, B., Kurpas, D., Grochans, E., Kuszmar, G., Rotter, I., Żułtak-Bączkowska K., \& Karakiewicz, B. (2012). Psychosexual functioning of women after breast cancer therapy. Psychiatria Polska, 46, 51-56.

Nadolska, K., \& Sęk, H. (2007). Społeczny kontekst odkrywania wiedzy o zasobach odpornościowych, czyli czym jest resilience i jak ono funkcjonuje. [The social context of discovering knowledge about immune resources - what resilience is and how it works] In: Ł. Kaczmarek, A. Słysz (Eds.). Bliżej serca - zdrowie i emocje [Closer heart- health and emotions] (pp. 13 -37). Poznań: Wyd. UAM.

Ogińska-Bulik, N. (2013). The role of social support in posttraumatic growth in people struggling with cancer. Health Psychology Report, 1, 1-8. https://doi.org/10.5114/hpr.2013.40464

Ogińska-Bulik, N. (2011). The role of women's psychological resilience in adapting to cancer. Psychoonkologia, 1, 16-24. 
Ogińska-Bulik, N. (2010). Post-traumatic growth in cancer: the role of resilience. Polskie Forum Psychologiczne, 15, 125-139.

Ogińska-Bulik, N., \& Juczyński, Z. (2008). Skala Pomiaru Prężności - SPP-25 [Resilience Measurement Scale - SPP-25]. Nowiny Psychologiczne, 3, 39-56.

Okła, W., Steuden, S., \& Puzon, P. (2006). Ocena jakości własnego życia u kobiet po mastektomii [Life quality self-assessment in post-mastectomy women]. In W. Okła \& S. Steuden (Eds.), Jakość życia w chorobie [Quality of life in illness] (pp. 33-48). Lublin: Wydawnictwo KUL.

Ong, A. D., Zautra, A. J., \& Reid, M. C. (2010). Psychological resilience predicts decreases in pain catastrophizing through positive emotions. Psychol Aging, 25, 516-523. https://doi.org/10.1037/ a0019384

Ostrowski, T. M. (2014). Resilience in the light of research and theoretical reflection. In T. M. Ostrowski \& I. Sikorska (Eds.), Health and resilience (pp. 13-23). Kraków: Jagiellonian University.

Pikler, V., \& Winterowd, C. (2003). Racial and body image differences in coping for women diagnosed with breast cancer. Health Psychology, 22, 632-637.

Sakson-Obada, O. (2009a). Pamięć ciata. Ja cielesne $w$ relacji przywiqzania $i$ w traumie [Memory of the body. Body self in attachment and trauma]. Warszawa: Difin.

Sakson-Obada, O. (2009b). Trauma jako czynnik ryzyka dla zaburzeń Ja cielesnego [Trauma as a risk factor for body-self disorders]. Przeglad Psychologiczny, 52, 309-326.

Semmer, N. K. (2006). Personality, stress and coping. In M. E. Vollrath (Ed.), Handbook of personality and health (pp. 73-113). Hoboken, NJ: John Wiley and Sons.

Sęk, H., \& Cieślak, R. (2004). Wsparcie spoteczne, stres i zdrowie [Social suport, stress and health]. Warszawa: PWN.

Sheppard, L. A., \& Ely, S. (2008). Breast cancer and sexuality. The Breast Journal, 14, 176-181. https:// doi.org/10.1111/j.1524-4741.2007.00550.x

Stanton, A. L., Danoff-Burg, S., \& Huggins, M. E. (2002). The first year after breast cancer diagnosis: Hope and coping strategies as predictors of adjustment. Psycho-Oncology, 11, 93-102.

Tarnopolska, M. (2007). Wizerunek ciała i jakość życia u kobiet po mastektomii. [Body image and quality of life in women after mastectomy]. Opole: Unpublished master's thesis.

Tedeschi, R. G., Park, C. L., \& Calhoun, L. G. (1998). Posttraumatic growth: Positive changes in the aftermath of crisis. Mahwah, NJ: Lawrence Erlbaum Associates.

Tedeschi, R. G., \& Calhoun, L. G. (2006). Expert companions: Posttraumatic growth in clinical practice. In L. G. Calhoun \& R. G. Tedeschi (Eds.), Handbook of posttraumatic growth: Research and practice (pp. 291-310). Mahwah, NJ: Lawrence ErIbaum Associates.

Tugade, M., \& Fredrickson, B. L. (2004). Resilient individuals use positive emotions to bounce back from negative emotional experiences. Journal of Personality and Social Psychology, 86, 320-333.

Tugade, M. M., \& Fredrickson, B. L. (2007). Regulation of positive emotions: Emotion regulation strategies that promote resilience. Journal of Happiness Studies, 8, 311-333.

Tykkä, E., Asko-Seljavaara, S., \& Hietanen, H. (2002). Patient satisfaction with delayed breast reconstruction: a prospective study. Annals of Plastic Surgery, 49, 258-263.

Vishnevsky, T., Cann, A., Calhoun, L. G., Tedeschi, R. G., \& Demakis, G. J. (2010). Gender differences in selfreported posttraumatic growth: A meta-analysis. Psychology of Women Quarterly, 34, 110-120.

Walden-Gałuszko de, K., Majkowicz, M., Trojanowski, L., \& Trzebiatowska, I. (1994). Jakość życia u kobiet z nowotworem gruczołu piersiowego [Quality of life in women with breast cancer]. In K. de Walden-Gałuszko \& M. Majkowicz (Eds.), Jakość życia w chorobie nowotworowej (pp. 105-112). Gdańsk: Wydawnictwo Uniwersytetu Gdańskiego.

Wallace, M. L., Harcourt, D., Rumsey, N., \& Foot, A. (2007). Managing appearance changes resulting from cancer treatment: resilience in adolescent females. Psycho-Oncology, 16, 1019-1027.

Waugh, C. E., Thompson, R. J., \& Gotlib, I. H. (2011). Flexible emotional responsiveness in trait resilience. Emotion, 11, 1059-1067. https://doi.org/10.1037/ a0021786

Widera, A., Juczyński, Z., \& Popiela, T. (2003). Psychological determinants of post-traumatic stress in oncological patients after scarring surgeries. Psychoonkologia, 7, 31-36.

Życińska, J. (2005). Znaczenie poczucia własnej skuteczności w kształtowaniu obrazu siebie i jakości związku małżeńskiego przez kobiety po mastektomii [The importance of self-efficacy among women after mastectomy in creating their self-concept and for their marital quality]. In D. Kubacka-Jasiecka \& T. M. Ostrowski (Eds.), Psychologiczny wymiar zdrowia, kryzysu i choroby [Psychological aspects of health, crisis and illness] (pp. 221-239). Kraków: Wydawnictwo Uniwersytetu Jagiellońskiego.

Zemore, R., \& Shepel, L. F. (1989). Effects of breast cancer and mastectomy on emotional support and adjustment. Social Science \& Medicine, 28, 19-27.
Psychological resilience and body image after mastectomy 